\title{
Combination of SIRTI and Src overexpression suggests poor prognosis in luminal breast cancer
}

This article was published in the following Dove Press journal:

OncoTargets and Therapy

\author{
Jie $\operatorname{Tan}^{1, *}$ \\ Yuyin $\mathrm{Liu}^{2}$,* \\ Yusufu Maimaiti ${ }^{3}$ \\ Changwen Wang' \\ Yu Yan' \\ Jing Zhou' \\ Shengnan Ruan' \\ Tao Huang' \\ 'Department of Breast and Thyroid \\ Surgery, Union Hospital, Tongji \\ Medical College, Huazhong University \\ of Science and Technology, Wuhan, \\ China; ${ }^{2}$ Department of Clinical \\ Laboratory, Union Hospital, Tongji \\ Medical College, Huazhong University \\ of Science and Technology, Wuhan, \\ China; ${ }^{3}$ Department of General \\ Surgery, Research Institute of \\ Minimally Invasive, People's Hospital \\ of Xinjiang Uygur Autonomous \\ Region, Urumqi, China \\ *These authors contributed equally \\ to this work
}

Correspondence: Tao Huang; Shengnan Ruan

Department of Breast and Thyroid Surgery, Union Hospital, Tongji Medical College, Huazhong University of Science and Technology, Wuhan 430022, China

Tel +86278575 I622

Email huangtaowh@163.com; ruanshengnan@yahoo.com
Objectives: 1) Analyze the correlation of SIRT1 and Src with human breast cancer (BC) prognosis; 2) explore the roles of SIRT1 and Src in BC cell proliferation, tumor invasion, and metastasis; and 3) analyze the correlation and interaction between SIRT1 and Src.

Materials and methods: 1) Tissue microarray was used to analyze the expression of SIRT1 and $\mathrm{Src}$ in human $\mathrm{BC}$ tissues and the correlation between protein expression and cancer prognosis; 2) CCK8 assay was used to determine the influence of SIRT1 and Src inhibitors on BC cell proliferation; 3) Transwell migration assay and wound healing assay were used to determine the effect of SIRT1 and Src inhibitors on BC cell migration and invasion; and 4) Western blotting was used to analyze the correlation and interaction between SIRT1 and Src.

Results: 1) Combination of SIRT1 and/or Src positivity is a prognosis factor in BC, especially in luminal type; 2) MCF-7 cell proliferation is suppressed by SIRT1 inhibitor Ex527, and cell migration and invasion were inhibited by Src inhibitor bosutinib; 3) combined with Ex527, bosutinib has a significantly increased effect on MCF-7 cell migration suppression; and 4) there is a positive association between SIRT1 and Src both in BC tissues and in MCF-7 cells.

Conclusion: 1) SIRT1 and Src overexpression are both correlated with poor prognosis in human BC; 2) SIRT1 + Src (SIRT1 and/or Src positivity) is a fine prognosis model for luminal-type BC; 3) SIRT1 is a copromotor of Src in BC migration and invasion, but not in cell proliferation; and 4) our results suggest a potential interaction or a common regulation pathway between SIRT1 and Src expression and activity.

Keywords: breast cancer, SIRT1, Src, tissue microarray, estrogen receptor, cell migration

\section{Introduction}

Breast cancer (BC) is the most frequently diagnosed cancer and cause of cancer death among women worldwide, with 1.7 million new cases and over 520,000 deaths recorded in $2012 .{ }^{1-3}$ BC comprises more than 20 distinct subtypes that differ genetically, morphologically, and clinically. ${ }^{4}$ Despite the increased understanding of $\mathrm{BC}$ complexity, therapeutic approaches are currently largely based on clinical and pathological BC features, supplemented by hormone receptor and HER2 status, which was first systematically reported in 2000..$^{5}$ The hormone receptor-positive BC subtype, typically addressed as luminal-type breast cancer (LBC), accounts for around 70\% of total $\mathrm{BC}$ cases, and is expected to have relatively better outcome after standard therapy. However, there are increasing numbers of LBC patients every year. A novel prognosis factor and better understanding of LBC oncogenesis may help improving BC patients' outcome.

SIRT1, a proto-member of the sirtuin family, is an NAD+-dependent histone deacetylase. SIRT1 modifies histones and nonhistone proteins through deacetylation. ${ }^{6}$ SIRT1 plays pivotal roles in a variety of physiological processes, such as cell 
metabolism, proliferation, senescence, apoptosis, and tumorigenesis. ${ }^{6,7}$ It exercises its functions through p53, FoxO1, NF- $\kappa \mathrm{B}$, and other signaling pathways..$^{8-10}$ Our previous publication has demonstrated that overexpression of SIRT1 correlates with poor prognosis in several solid tumors, including lung cancer and liver cancer. ${ }^{11}$ However, the role of SIRT1 in LBC oncogenesis has not yet reached a conclusion. Elangovan et $\mathrm{l}^{12}$ reported that SIRT1 is critical for estrogen to promote BC, and the combination of SIRT1 inhibitors and antiestrogen compounds may offer more effective treatment strategies for LBC. But, Moore and Faller ${ }^{13}$ reported that SIRT1 represses the transcriptional and proliferative response of LBC cells to estrogen.

Src, the most investigated isoform in the Src family kinases, is a nonreceptor tyrosine kinase that acts downstream of receptor tyrosine kinases and integrins in the regulation of various stages of tumor cell proliferation and survival. It plays a definitive role in tumor metastasis by regulating earlier stages of cell proliferation such as cell migration, adhesion, and invasion. ${ }^{14}$ Previous studies have demonstrated that Src plays an important role in LBC development. High expression levels of cytoplasmic Src was associated with worse LBC-specific survival after completing 5 years of tamoxifen therapy, while this high expression did not show any association with de novo tamoxifen resistance. ${ }^{15}$ Combination therapies using both endocrine agents and Src inhibitors may have better therapeutic effect by delaying the development of hormonal resistance. ${ }^{16}$

In this study, we analyzed the correlation of SIRT1 and Src expression with human BC clinical factors and prognosis. Using cell proliferation assay and migration assay, we demonstrated the potential functional roles of SIRT1 and Src in LBC. Our results may make contributions to a better understanding of LBC oncogenesis, developing new targeting molecule, and improving LBC patients' clinical outcome.

\section{Materials and methods \\ Tissue microarray and immunohistochemical staining}

Two tissue microarrays containing 268 BC tissue specimens in total were purchased from the National Engineering Center for BioChips (Shanghai, People's Republic of China). All specimens and clinical information were obtained from Zhejiang Taizhou Hospital. Ethical approval for the present study was granted by the Human Research Ethics Committee of the Taizhou Hospital. We used SIRT1-specific antibody (\#8469; Cell Signaling Technology, Danvers, MA, USA) at a 1:25 dilution and Src-specific antibody (\#2109; Cell
Signaling Technology) at a 1:50 dilution for SIRT1 and Src expression evaluation. Immunohistochemical staining was independently evaluated by two experienced pathologists blinded to the clinical information. The protein expression levels were graded as described previously. ${ }^{17,18}$ SIRT1 staining intensity in the cytoplasm of tumor cells was graded $0-3$. The percentage of SIRT1-positive cells was scored as 0-4 (0\%-5\%, 6\%-25\%, 26\%-50\%, 51\%-75\%, and 76\%-100\%, respectively). The final SIRT1 expression score was graded as strong expression (overexpression) or weak expression, based on the sum of the intensity and percent positive scores (0-4 and $>5$, respectively; Figure 1). The expression of Src was also graded as strong (overexpression; high staining intensity, $>10 \%$ ) or weak expression (low staining intensity, $\leq 10 \%$ ). The slides were scanned using a ScanScope slide scanner (Aperio, Vista, CA, USA), and as in Figure 1, images of representative areas were acquired using Image Scope software (Aperio) and analyzed using Illustrator (Adobe, San Jose, CA, USA).

\section{Cell culture and transfection}

The human LBC-derived cell line, MCF-7, was obtained from the Chinese Academy of Sciences (Shanghai, People's Republic of China). Cells were cultured in Dulbecco's Modified Eagle's Medium (DMEM) high-glucose medium (Thermo Fisher Scientific, Waltham, MA, USA) supplemented with $10 \%$ fetal bovine serum (FBS; Thermo Fisher Scientific) in a $5 \% \mathrm{CO}_{2}$ atmosphere at $37^{\circ} \mathrm{C}$ and used within 2 months after resuscitation of frozen aliquots. $\mathrm{MCF}-7$ cells $\left(3 \times 10^{5} /\right.$ well $)$ were seeded onto a 6-well plate containing $1 \mathrm{~mL}$ Opti-MEM (Thermo Fisher Scientific) $24 \mathrm{~h}$ before transfection. Ten microliters of $20 \mathrm{mM}$ siRNA (SIRT1: CCAUCUCUCUGUCACAAAUTT; Src: CCAAGGGCCUCAACGUAA) or negative control siRNA (UUCUCCGAACGUGUCACGUTT) and $10 \mathrm{~mL}$ of Lipofectamine 2000 (Thermo Fisher Scientific) were added and gently mixed. The plate was then incubated for $48 \mathrm{~h}$ before further assays.

\section{Cell migration assay}

\section{Transwell assay}

MCF-7 cells were starved for $6 \mathrm{~h}$ in DMEM with $1 \%$ FBS. Top chambers of 24-well Transwell plates (Corning, Corning, NY, USA) were pretreated with 1\% matrigel (BD Biosciences, Franklin Lakes, NJ, USA) in phosphatebuffered saline and incubated for $1 \mathrm{~h}$ at room temperature. Transfected and untransfected cells were added to the top chambers of the plates. Medium with specific concentration of SIRT1 inhibitor $\operatorname{Ex} 527(0.2,1,5 \mu \mathrm{mol} / \mathrm{L})^{19}$ and 

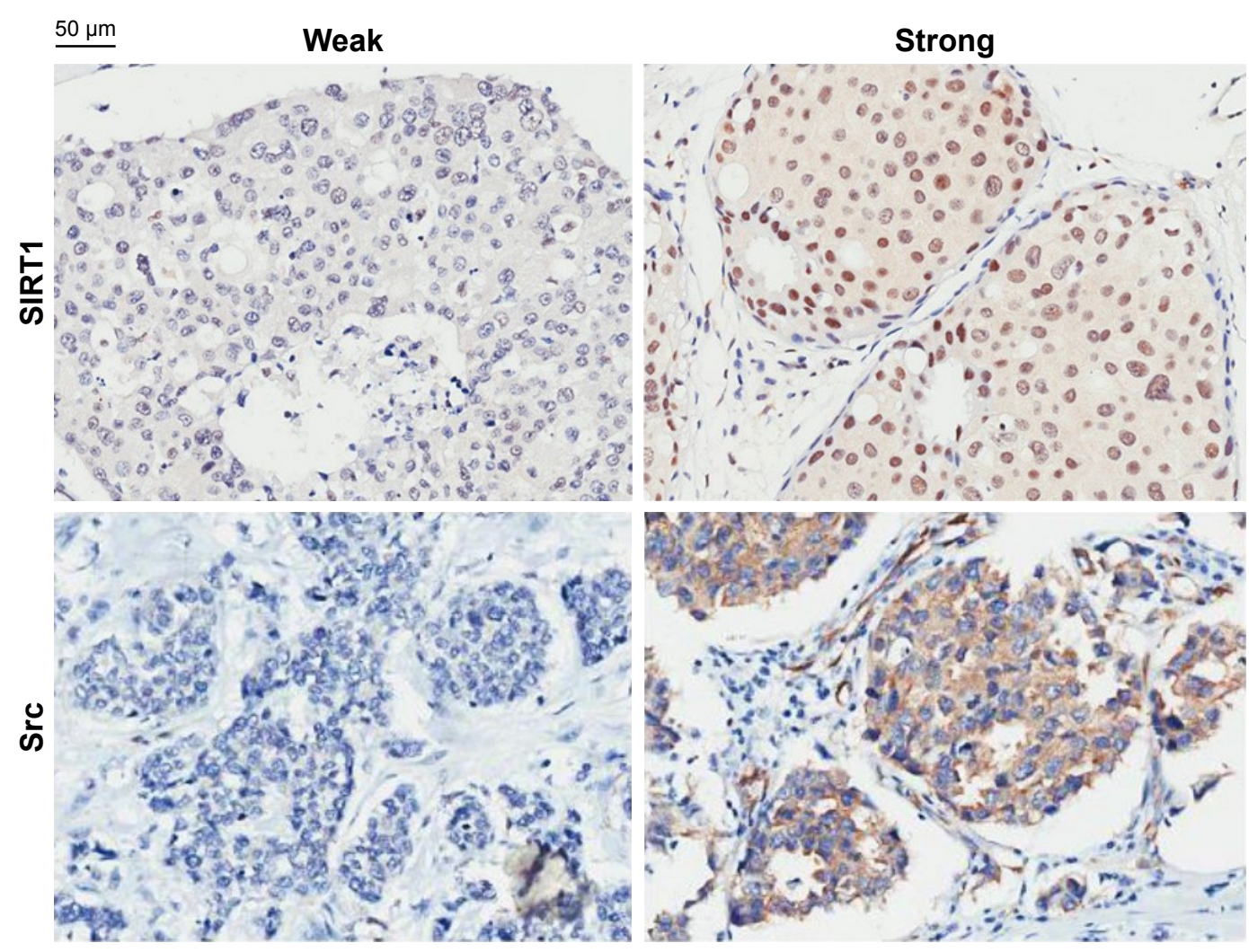

Figure I Examples of scoring of immunohistochemistry staining of SIRTI and Src expression in BC tissue.

Note: Magnification $\times 200$.

Abbreviation: BC, breast cancer.

Src inhibitor bosutinib $(50,250,1,250 \mathrm{nmol} / \mathrm{L})^{20}$ and their combinations (both purchased from Selleck Chemicals, Houston, TX, USA) were added to both chambers. After 24 $\mathrm{h}$ of incubation, the cells on the top were removed and the cells on the bottom of the filter were fixed and stained with $2 \%$ crystal violet solution in ethanol (Beyotime Biotechnology, Shanghai, People's Republic of China). The number of migrating cells was counted in 5 fields under an IX71 fluorescence microscope (Olympus, Tokyo, Japan), and the mean for each chamber was determined. Results are shown as the average of at least 3 independent experiments.

\section{Wound healing assay}

The transfected MCF-7 cells were seeded into 6-well plates $\left(5 \times 10^{5} /\right.$ well). After the cell adherence with the monolayer, scratches were performed by a sterile tip $(200 \mu \mathrm{L})$. Sterile phosphate-buffered saline was used to wash the cells twice to remove scraped cells. The medium was then replaced with $1 \%$ FBS medium with specific concentration of Ex527 (0.2, 1, $5 \mu \mathrm{mol} / \mathrm{L})$ and Bosutinib $(50,250,1,250 \mathrm{nmol} / \mathrm{L})$ and their combinations. The scratch distance was observed, photographed, and recorded after 0,12 and $24 \mathrm{~h}$. Results are shown as the average of at least 3 independent experiments.

\section{Cell proliferation assay: CCK-8 assay}

CCK-8 (Dojindo Molecular Technologies, Kumamoto, Japan) was used to perform cell proliferation assay, according to the manufacturer's instruction. MCF-7 cells were treated with specific concentrations of Ex527 (0.2, 1, $5 \mu \mathrm{mol} / \mathrm{L})$, bosutinib $(50,250,1,250 \mathrm{nmol} / \mathrm{L})$, and their combinations after being seeded in 96 -well culture plates ( 3,000 cells/well). Following treatment for 0,12 , and $24 \mathrm{~h}, 100 \mu \mathrm{L}$ of $10 \%$ CCK-8 reagent-DMEM medium was added into each well and incubated with the cells for another $60 \mathrm{~min}$. The absorbance at $450 \mathrm{~nm}$ was measured for each well with a Multiskan $^{\mathrm{TM}}$ GO Microplate Spectrophotometer (Thermo Fisher Scientific). Results are shown as the average of at least 3 independent experiments.

\section{Cell lysis and Western blotting}

Cell lysis and Western blotting were performed as previously described, ${ }^{21}$ using antibodies against SIRT1 (\#8469; Cell Signaling Technology), Src (\#2109; Cell Signaling Technology), and GAPDH (\#5174; Cell Signaling Technology). The chemiluminescent blots were imaged with the Molecular Imager ChemiDoc ${ }^{\mathrm{TM}}$ XRS (Bio-Rad, Hercules, CA, USA), and ImageLab software version 4.1 (Bio-Rad) 
was used to select and determine the background-subtracted density of the bands in all the blots.

\section{Statistical analysis}

Student's $t$-test was used to compare groups, and Pearson's $\chi^{2}$ test to assess the correlation between variables. Cox regression proportional hazards model was used to estimate hazard ratios (HRs) for BC-specific death based on SIRT1 and Src expression. All analyses were performed using SPSS Statistics version 19 software (IBM Corporation, Armonk, NY, USA). All statistical tests were 2-sided, and a $P$-value $<0.05$ was considered statistically significant.

\section{Results}

\section{Correlations between SIRTI, Src, clinicopathological characteristics, and prognosis}

As shown in Table 1, SIRT1 expression did not show any significant correlation with patient age, tumor $\mathrm{T}$ or $\mathrm{N}$ category,

Table I Correlations between SIRTI, Src, and clinicopathological characteristics

\begin{tabular}{|c|c|c|c|c|}
\hline \multicolumn{5}{|l|}{$\overline{\text { SIRTI }}$} \\
\hline & $\mathbf{N}$ & Weak & Strong & $P$-value \\
\hline $\bar{N}(\%)$ & $268(100)$ & $216(80)$ & $52(20)$ & \\
\hline Age (years) & & & & $0.358^{\mathrm{a}}$ \\
\hline Medium (range) & $54(29-88)$ & 54.5 (29-88) & $54(33-87)$ & \\
\hline $\mathrm{T}$ category & & & & $0.105^{\mathrm{b}}$ \\
\hline TI (\%) & $64(24)$ & $55(86)$ & $9(14)$ & \\
\hline T2 (\%) & $17 \mid(64)$ & $138(8 \mid)$ & $33(19)$ & \\
\hline T3/T4 (\%) & $27(10)$ & $18(67)$ & $9(33)$ & \\
\hline Missing (\%) & $6(2)$ & & & \\
\hline $\mathrm{N}$ category & & & & $0.866^{\mathrm{b}}$ \\
\hline No (\%) & II (44) & $94(80)$ & $23(20)$ & \\
\hline NI (\%) & $75(28)$ & $62(83)$ & $13(17)$ & \\
\hline N2/N3 (\%) & $70(26)$ & $56(80)$ & $14(20)$ & \\
\hline Missing (\%) & $6(2)$ & & & \\
\hline NHG & & & & $0.902^{\mathrm{b}}$ \\
\hline I (\%) & $44(16)$ & $36(82)$ & $8(18)$ & \\
\hline II (\%) & $16 \mid(60)$ & $129(80)$ & $32(20)$ & \\
\hline III (\%) & $55(21)$ & $43(78)$ & $12(22)$ & \\
\hline Missing (\%) & $8(3)$ & & & \\
\hline ER & & & & $0.87 I^{b}$ \\
\hline Positive (\%) & $176(66)$ & $|4|$ (80) & $35(20)$ & \\
\hline Negative (\%) & $92(34)$ & $75(82)$ & $17(19)$ & \\
\hline Missing (\%) & 0 & & & \\
\hline PR & & & & $0.09 I^{b}$ \\
\hline Positive (\%) & $\mid 36(5 \mid)$ & 104 (77) & $32(24)$ & \\
\hline Negative (\%) & 132 (49) & 112 (85) & $20(15)$ & \\
\hline Missing (\%) & 0 & & & \\
\hline Ki67 & & & & $0.404^{b}$ \\
\hline$>14 \%(\%)$ & $83(3 \mathrm{I})$ & $64(77)$ & $19(23)$ & \\
\hline$\leq 14 \%(\%)$ & $185(69)$ & $152(82)$ & $33(18)$ & \\
\hline Missing (\%) & 0 & & & \\
\hline
\end{tabular}

(Continued)
Table I (Continued)

\begin{tabular}{|c|c|c|c|c|}
\hline \multicolumn{5}{|l|}{ SIRTI } \\
\hline & $\mathbf{N}$ & Weak & Strong & $P$-value \\
\hline HER2 & & & & $0.362^{b}$ \\
\hline Strong (\%) & $63(23)$ & $48(76)$ & $15(24)$ & \\
\hline Weak (\%) & $205(77)$ & $168(82)$ & $37(18)$ & \\
\hline Missing (\%) & 0 & & & \\
\hline CK5/6 & & & & $0.702^{\mathrm{b}}$ \\
\hline Positive (\%) & $55(2 I)$ & $43(78)$ & $12(22)$ & \\
\hline Negative (\%) & $213(79)$ & I73 (8I) & $40(19)$ & \\
\hline Missing (\%) & 0 & & & \\
\hline \multicolumn{5}{|l|}{ Src } \\
\hline & $\mathbf{N}$ & Weak & Strong & $P$-value \\
\hline N (\%) & $224(100)$ & II 8 (53) & $106(47)$ & \\
\hline Age (years) & & & & $0.612^{\mathrm{a}}$ \\
\hline Medium (range) & 54 (29-87) & $54(29-87)$ & $54.5(3 \mid-86)$ & \\
\hline T category & & & & $0.018^{b}$ \\
\hline TI (\%) & $56(24)$ & $38(68)$ & $18(32)$ & \\
\hline T2 (\%) & $140(62)$ & $64(46)$ & $76(54)$ & \\
\hline T3/T4 (\%) & $23(10)$ & II (48) & $12(52)$ & \\
\hline Missing (\%) & $5(2)$ & & & \\
\hline $\mathrm{N}$ category & & & & $0.237^{b}$ \\
\hline No (\%) & $96(43)$ & $57(59)$ & $39(4 I)$ & \\
\hline NI (\%) & $64(28)$ & $30(47)$ & $34(53)$ & \\
\hline N2/N3 (\%) & $59(25)$ & $29(49)$ & $30(5 I)$ & \\
\hline Missing (\%) & $5(2)$ & & & \\
\hline NHG & & & & $0.806^{b}$ \\
\hline I (\%) & $34(15)$ & $19(56)$ & $15(44)$ & \\
\hline II (\%) & $139(62)$ & $71(5 I)$ & $68(49)$ & \\
\hline III (\%) & $45(20)$ & $25(56)$ & $20(44)$ & \\
\hline Missing (\%) & $6(3)$ & & & \\
\hline ER & & & & $0.264^{b}$ \\
\hline Positive (\%) & $146(65)$ & $81(56)$ & $65(44)$ & \\
\hline Negative (\%) & $78(35)$ & $37(47)$ & $4 I(53)$ & \\
\hline Missing (\%) & 0 & & & \\
\hline PR & & & & $0.894^{b}$ \\
\hline Positive (\%) & II $5(5 \mathrm{I})$ & $60(52)$ & $55(48)$ & \\
\hline Negative (\%) & $109(49)$ & $58(53)$ & $5 I(47)$ & \\
\hline Missing (\%) & 0 & & & \\
\hline Ki67 & & & & $0.144^{b}$ \\
\hline$>14 \%(\%)$ & $67(30)$ & $30(45)$ & $37(55)$ & \\
\hline$\leq 14 \%(\%)$ & $157(70)$ & $88(56)$ & $69(44)$ & \\
\hline Missing (\%) & 0 & & & \\
\hline HER2 & & & & $0.018^{b}$ \\
\hline Strong (\%) & $53(24)$ & $20(38)$ & $33(62)$ & \\
\hline Weak (\%) & $|7|(76)$ & $98(57)$ & $73(43)$ & \\
\hline Missing (\%) & 0 & & & \\
\hline CK5/6 & & & & $0.742^{\mathrm{b}}$ \\
\hline Positive (\%) & $46(20)$ & $23(50)$ & $23(50)$ & \\
\hline Negative (\%) & $178(80)$ & $95(53)$ & $83(47)$ & \\
\hline Missing (\%) & 0 & & & \\
\hline
\end{tabular}

Notes: a One-factor ANOVA. bPearson's $\chi^{2}$ test, 2-tailed P-value. Abbreviations: ANOVA, analysis of variance; NHG, Nottingham histological grade; $E R$, estrogen receptor; PR, progesterone receptor.

histological grade, or any other pathological characteristics, including ER, PR, Ki67, Her2, or CK5/6. Src overexpression showed significant positive correlation with tumor T category and Her2 overexpression; the $P$-values were 0.018 and 0.018 , 
Table 2 Correlations between SIRTI and Src expression in breast cancer

\begin{tabular}{llll}
\hline Src & SIRTI & & \\
\cline { 2 - 4 } & Weak & Strong & P-value \\
\hline Strong (\%) & $76(72)$ & $30(28)$ & 0.004 \\
Weak (\%) & $103(87)$ & $15(13)$ & \\
\hline
\end{tabular}

Note: Pearson's $\chi^{2}$ test, 2 -tailed $P$-value.

respectively. However, SIRT1 and Src expression showed a significant positive association with each other, which suggested that SIRT1 overexpression patients tend to have a relatively high $\mathrm{Src}$ expression, and the $P$-value was 0.004 (Table 2).

As indicated in Table 3, various clinicopathological characteristics, including SIRT1 and Src, had a correlation with prognosis. Among them, SIRT1 and Src overexpression and higher $\mathrm{T}$ category and $\mathrm{N}$ category correlated with relatively poor outcome in BC. The HR and $95 \%$ confidential interval (95\% CI) were 1.855 (1.14-3.01), 1.735 (1.06-2.83), 1.563 (1.04-2.35), and 1.409 (1.08-1.84), respectively. While ER and $\mathrm{PR}$ positivity indicated a better $\mathrm{BC}$ prognosis, the HR and $95 \% \mathrm{CI}$ were found to be $0.612(0.39-0.95)$ and 0.483 (0.31-0.76). In our results, Her2, Ki67, and Nottingham histology grade did not show any correlation with $\mathrm{BC}$ prognosis.

Using Kaplan-Meier analysis and log-rank test, we evaluated the correlations between SIRT1 overexpression and

Table 3 Correlations between SIRTI, Src, clinicopathological characteristics, and prognosis

\begin{tabular}{|c|c|c|c|c|}
\hline \multirow[t]{2}{*}{ Variants } & \multicolumn{4}{|c|}{ Single-factor analysis } \\
\hline & $\mathbf{N}$ & HR & $95 \% \mathrm{Cl}$ & $P$-value \\
\hline SIRTI (strong vs weak) & 268 & 1.855 & $1.14-3.01$ & 0.012 \\
\hline Src (strong vs weak) & 224 & 1.735 & $1.06-2.83$ & 0.027 \\
\hline SIRTI + Src (strong vs weak) & 221 & 2.218 & $1.32-3.73$ & 0.003 \\
\hline T category (TI vs $\mathrm{T} 2$ vs $\mathrm{T} 3 / \mathrm{T} 4)$ & 262 & 1.563 & $1.04-2.35$ & 0.032 \\
\hline $\mathrm{N}$ category (N0 vs NI vs N2/N3) & 262 & 1.409 & $1.08-1.84$ & 0.011 \\
\hline ER (positive vs negative) & 268 & 0.612 & $0.39-0.95$ & 0.029 \\
\hline PR (positive vs negative) & 268 & 0.483 & $0.31-0.76$ & 0.002 \\
\hline Her2 (strong vs weak) & 268 & 1.178 & $0.7 I-1.95$ & 0.525 \\
\hline Ki67 (>I4\% vs $\leq 14 \%)$ & 268 & 1.203 & $0.76-1.91$ & 0.433 \\
\hline NHG (I vs II vs III) & 260 & 1.138 & $0.78-1.65$ & 0.495 \\
\hline \multirow[t]{2}{*}{ Variants } & \multicolumn{4}{|c|}{ Multiple-factor analysis } \\
\hline & $\mathbf{N}$ & HR & $95 \% \mathrm{Cl}$ & $P$-value \\
\hline SIRTI + Src (strong vs weak) & 215 & 2.045 & $1.19-3.51$ & 0.009 \\
\hline T category (TI vs $\mathrm{T} 2$ vs $\mathrm{T} 3 / \mathrm{T} 4)$ & 215 & 1.349 & $0.84-2.17$ & 0.218 \\
\hline $\mathrm{N}$ category (N0 vs NI vs N2/N3) & 215 & 1.354 & $1.00-1.83$ & 0.049 \\
\hline ER (positive vs negative) & 215 & 1.078 & $0.56-2.06$ & 0.822 \\
\hline PR (positive vs negative) & 215 & 0.496 & $0.26-0.95$ & 0.035 \\
\hline
\end{tabular}

Notes: SIRTI + Src strong indicates SIRTI and/or Src overexpression; SIRTI + Src weak indicates both SIRTI and Src are weakly expressed.

Abbreviations: $\mathrm{Cl}$, confidence interval; $\mathrm{HR}$, hazard ratio; NHG, Nottingham histological grade; ER, estrogen receptor; PR, progesterone receptor. prognosis in BC patients (Figure 2A). There was a significant association between SIRT1 overexpression and poor BC outcome: patients with SIRT1 overexpression tumor tend to have relative shorter total survival, and the $P$-value was 0.017 . There was a similar association between Src overexpression and poor prognosis ( $P=0.033$; Figure $2 \mathrm{~B}$ ).

As we previously described that SIRT1 and Src tend to overexpress in the same tumor, we tried to combine SIRT1 and Src expression as one prognosis factor. Our results showed that SIRT1 and Src co-overexpression patients had the worst $\mathrm{BC}$ outcome, but there was no significant difference between co-overexpression and only 1 overexpression. However, the patients with both SIRT1 and Src weak expression had the best prognosis, and the $P$-value was 0.006 (Figure 2C). Then, we defined a novel prognosis factor as "SIRT1 + Src": strong as SIRT1 and/or Src overexpression and weak as SIRT1 and Src underexpression. As indicated in Figure 2D, there are significant overall survival differences between strong SIRT1 + Src patients and the weak ones. The $P$-value was 0.002. The HR of SIRT $1+$ Src was 2.218 , with a $95 \%$ CI at $1.32-3.73$, and the $P$-value was 0.003 (Table 3 ). Using multifactor COX regression analysis, including SIRT1 + Src, T category, N category, ER, and PR, we found that SIRT1 + Src was an independent prognosis factor. The HR of strong SIRT1 + Src patients was 2.045 (1.19-3.51), and $P$-value was 0.009 . Higher $\mathrm{N}$ category and positive PR also remained as independent prognosis factors, with HRs at 1.354 (1.00-1.83) and $0.496(0.26-0.95)$, respectively. However, T category and ER showed no significant independent correlation with $\mathrm{BC}$ prognosis in this analysis.

When we analyzed the impact of SIRT1 + Src on survival in different subtypes of $\mathrm{BC}$ patients, we found that SIRT1 + Src was a prognosis factor only in LBC, with a significant $P$-value at 0.001 . In hormone-receptor negative BC patients, this significance disappeared with $P$-value at 0.330 (Figure 2E and F). There were $68 \mathrm{LBC}$ patients in the SIRT $1+$ Src weak expression group, and only 8 of them died in the 150 months of follow-up, while $31 \mathrm{LBC}$ patients died out of total 86 patients in the strong SIRT1 + Src group. In COX regression analysis, strong SIRT1 + Src showed an HR at 3.485 (1.60-7.58) in LBC patients, while the HR was $1.434(0.69-2.98)$ in non-LBC patients.

\section{MCF-7 cell proliferation is suppressed by Ex527 but not bosutinib}

We used CCK-8 assay to evaluate the potential inhibition effect of SIRT1 and Src inhibitors on cell proliferation. 

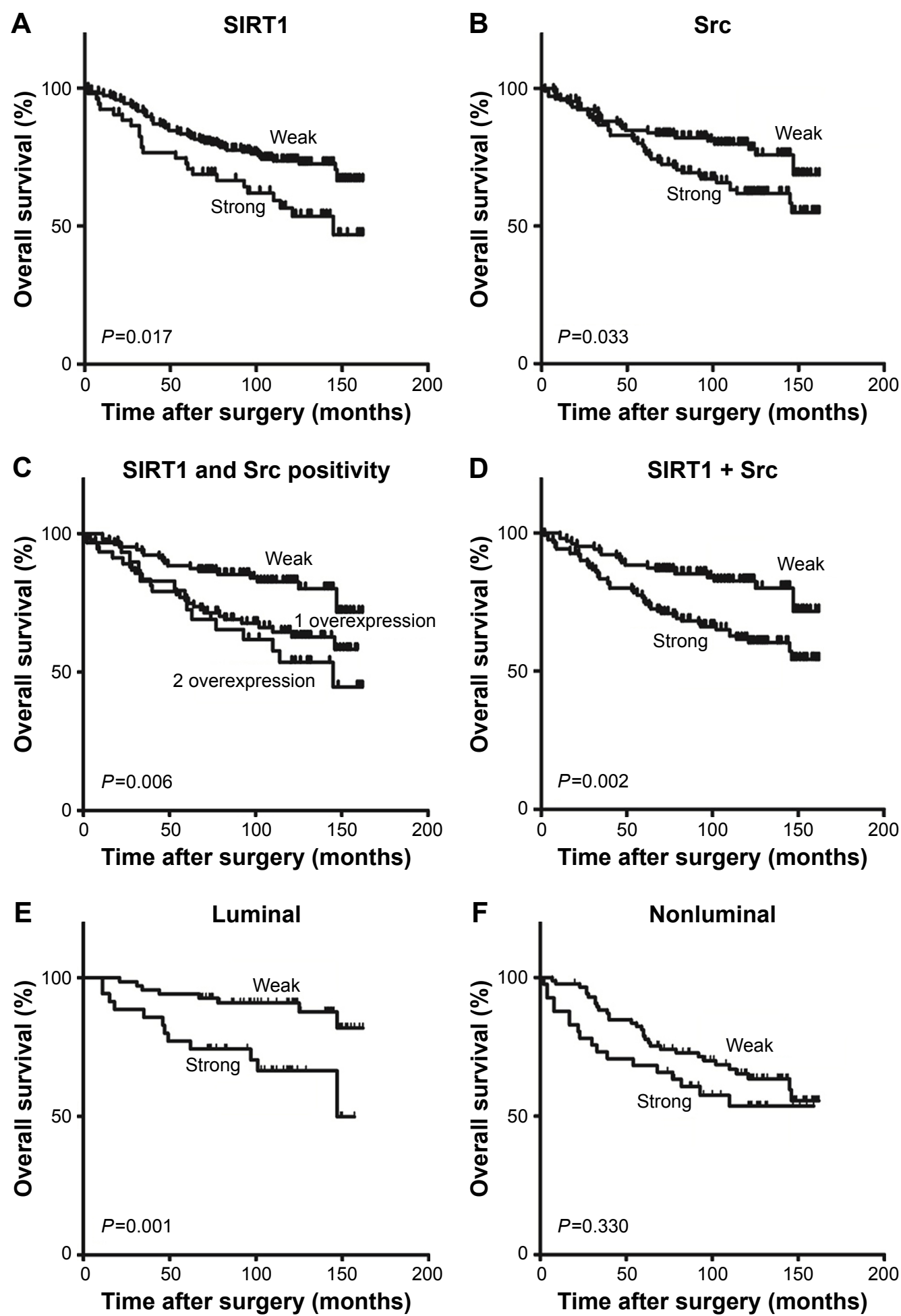

Figure 2 (A) SIRTI overexpression indicates poor survival in BCs. (B) Src overexpression indicates poor survival in BCs. (C) SIRTI and Src double overexpression indicates poorest outcome in BCs, while double weak expression patients have longest survival. (D) Different SIRTI + Src status suggest different overall survival. (E and F) SIRTI + Src status shows prognosis effect only in LBC patients.

Abbreviations: BC, breast cancer; LBC, luminal-type breast cancer.

As indicated in Figure 3A, SIRT1 inhibitor Ex527 shows a concentration-dependent growth inhibition in MCF-7 cells. This inhibition was statistically significant at $1 \mu \mathrm{M}$ and $5 \mu \mathrm{M}$ ( $P=0.049$ and 0.019 , respectively). While the small-molecule inhibitor of Src, bosutinib, did not show any growth inhibition effect after 24-hour treatment with different concentrations at 50,250 , and $1,250 \mathrm{nmol} / \mathrm{L}$ (Figure 3B), the combination of these 2 inhibitors in any concentration did not show 
A

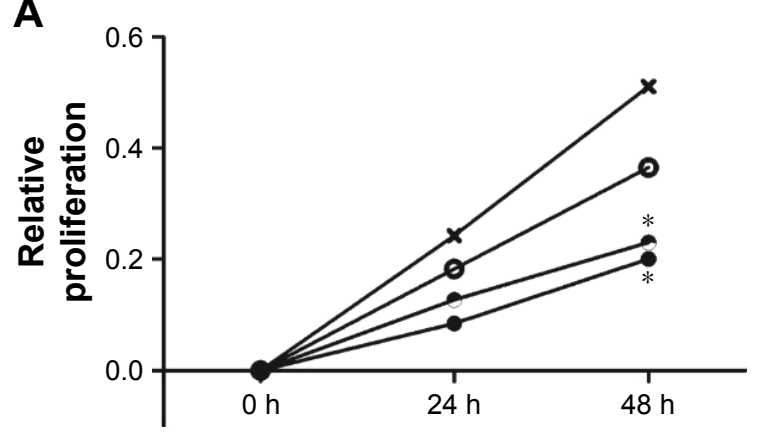

C

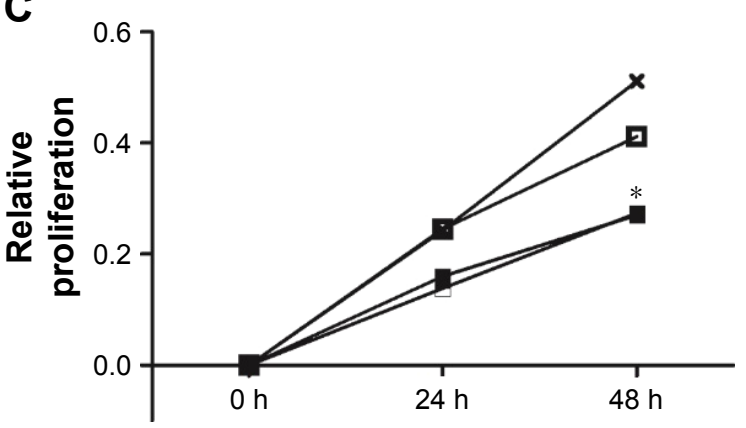

$\mathbf{E}$

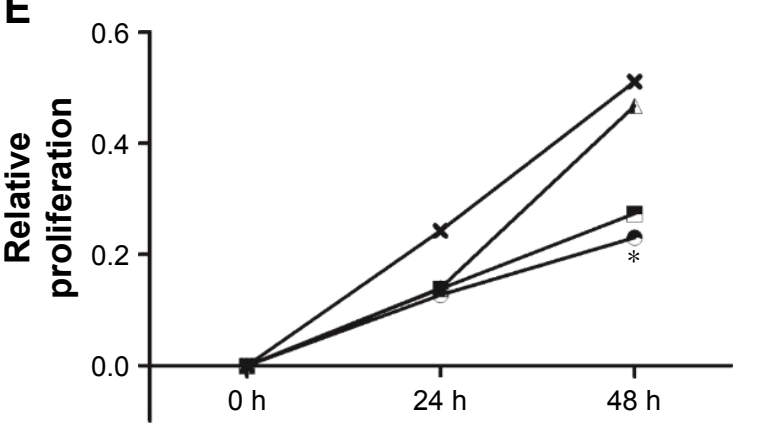

B

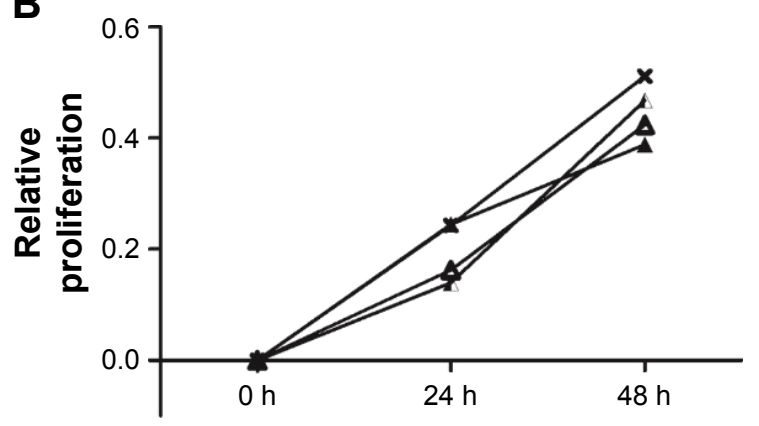

D

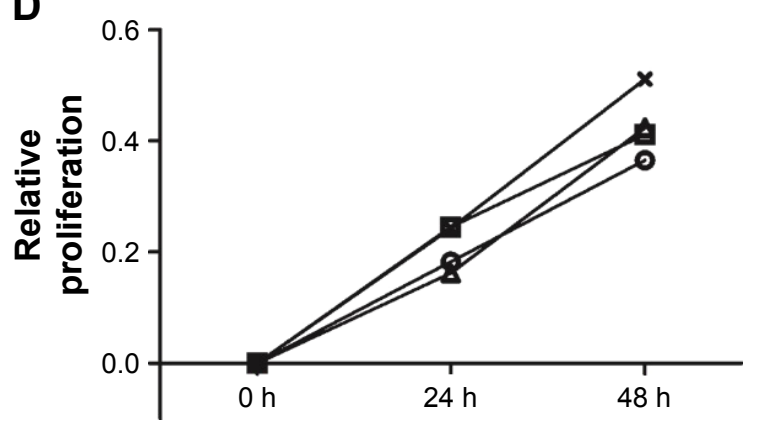

$\mathbf{F}$

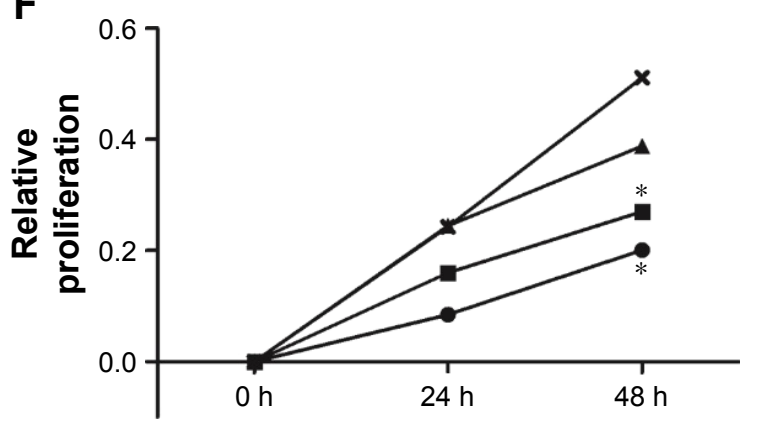

\begin{tabular}{|c|c|c|}
\hline & $\because$ - Blank & \\
\hline ๑- Ex527 $0.2 \mu \mathrm{M}$ & $\triangle$ Bosutinib $50 \mathrm{nM}$ & \# Ex527 0.2+ Bosutinib 50 \\
\hline - Ex527 $1 \mu \mathrm{M}$ & $\mp$ Bosutinib $250 \mathrm{nM}$ & - Ex527 1+ Bosutinib 250 \\
\hline$\rightarrow$ Ex527 $5 \mu \mathrm{M}$ & $\mp$ Bosutinib 1,250 nM & - Ex527 5+ Bosutinib 1,250 \\
\hline
\end{tabular}

Figure 3 CCK-8 assays indicate MCF-7 cell proliferation is suppressed by Ex527 but not bosutinib.

Notes: (A-C) Proliferation inhibition effect of different concentrations of Ex527 (A), bosutinib (B), and their combinations (C). (D-F) Proliferation inhibition effect of low (D), medium (E), or high $(\mathbf{F})$ concentration of Ex527, bosutinib, and their combinations. *P-value $<0.05$.

stronger cell proliferation inhibition than Ex527 alone (Figure 3C-F).

\section{Ex527 and bosutinib combination has increased effect on MCF-7 cell migration suppression}

As indicated in Figures 4 and 5, Ex527 alone had no significant inhibition on MCF-7 cell migration in 0.2 , 1 , or $5 \mu \mathrm{mol} / \mathrm{L}$, both in Transwell assay (Figure $4 \mathrm{~A}$ ) and wound healing assay (Figure 5A). Bosutinib shows a concentration-dependent cell migration suppression effect, and this effect was statistically significant in the 250 and $1,250 \mathrm{nM}$ concentration group in the Transwell assay (Figure 4B; $P=0.0001$ and $<0.0001$, respectively) and in the $1,250 \mathrm{nM}$ group in the wound healing assay (Figure 5B; $P=0.049$ ).

Our results showed there was a significantly increased migration suppression effect in the combination treatment group. In Transwell assay, $250 \mathrm{nM}$ bosutinib combined with $1 \mu \mathrm{M}$ Ex527 treatment showed a statistical significantly increased inhibition on MCF-7 cell migration, with $P=0.012$ (Figure 4D). In wound healing assay, 1,250 nM bosutinib combined with $5 \mu \mathrm{M}$ Ex 527 totally inhibited cell migration after 48-hour treatment compared to the blank control group, and the $P$-value was $<0.0001$ (Figure 5F). 
A

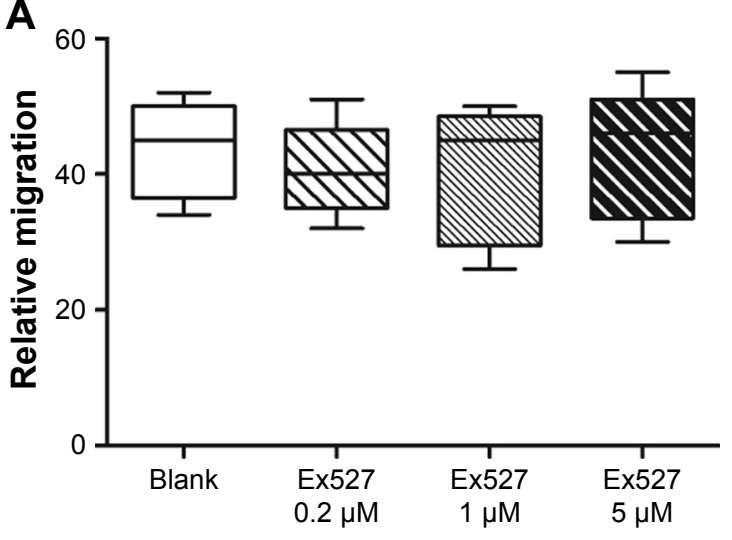

C

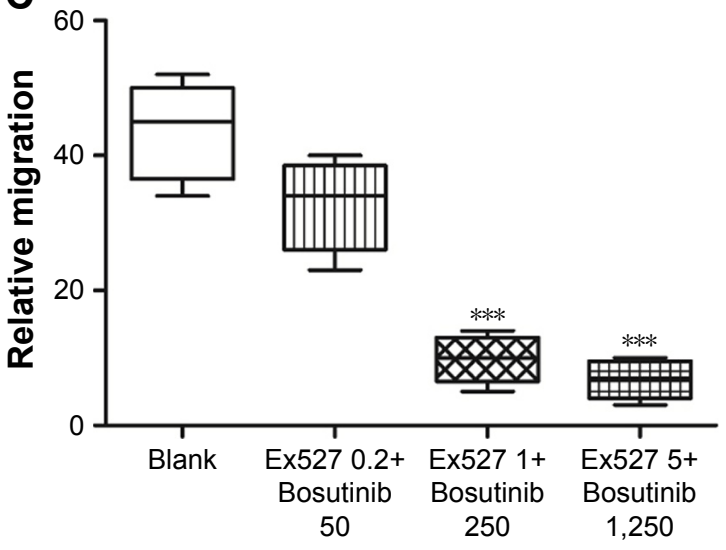

B

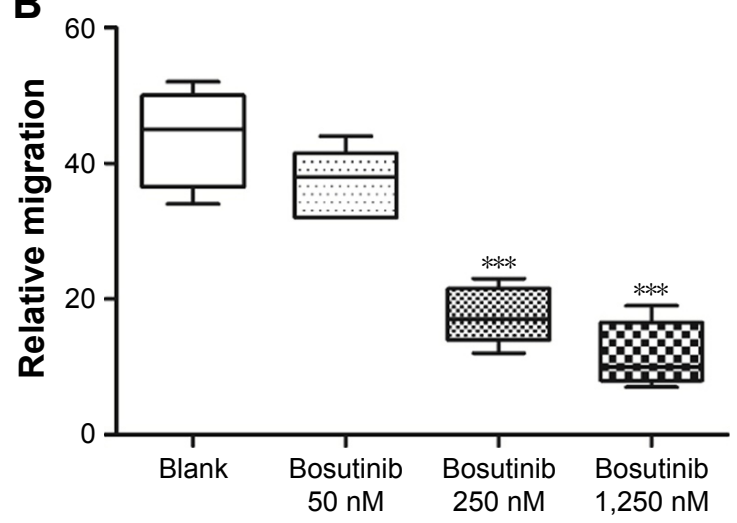

D

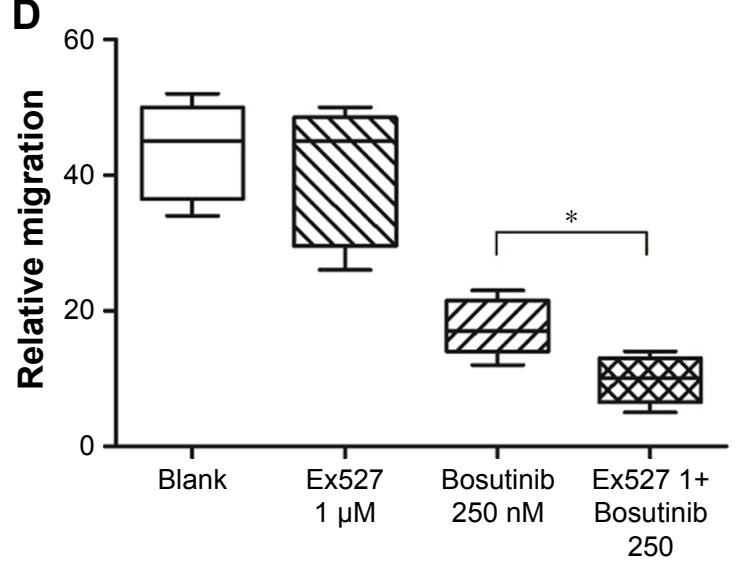

Figure 4 Transwell assays indicate MCF-7 cell migration is suppressed by bosutinib.

Notes: Ex527 and bosutinib combination has increased effect on cell migration suppression. (A-C) Migration inhibition effect measured by Transwell assay of different concentrations of Ex527 (A), bosutinib (B), and their combinations (C). (D) Migration inhibition effect of medium concentration of Ex527, bosutinib, and their combinations. $* P$-value $<0.05 ; * * * P$-value $<0.001$.

\section{Positive correlation between SIRTI and Src in MCF-7 cell}

As indicated in Figure 6, SIRT1-specific siRNA decreased the SIRT1 and Src protein expression in MCF-7 cell line. Src siRNA treatment also showed SIRT1 and Src protein expression suppression effect compared to control groups.

\section{Discussion}

In this study, we examined the correlations between SIRT1, Src, other clinicopathological factors, and human BC outcome. SIRT1 expression did not have a significant correlation with any other clinicopathological characteristics except for Src, including patient age, $\mathrm{T}$ category, $\mathrm{N}$ category, Nottingham histology grade, ER, PR, Her2, and Ki67 status. Src overexpression was associated with $\mathrm{T}$ category and Her2 status, which was supported by several previous studies. ${ }^{22,23}$ However, our results suggested that there was no significant correlation between Src overexpression and higher $\mathrm{N}$ category. This result did not agree with most previous studies on Src and cancer metastasis, which suggests that Src plays a definitive role in tumor metastasis by regulating cell migration, adhesion, and invasion. ${ }^{24-26}$ This result may be due to the following potential reasons: 1) this tissue microarray study contains 268 cases of BC tumors. Larger numbers of cases may help to gain more objective results. 2) Clinical $\mathrm{N}$ category depends not only on molecular biomarkers, which indicates tumor aggressiveness and metastasis tendency, but also correlates with the time interval between tumor formation and diagnosis or surgery. ${ }^{27}$

In single-factor $\mathrm{COX}$ regression analysis, higher $\mathrm{T}$ and $\mathrm{N}$ category both showed associations with poor outcome, which was supported by several previous studies. ${ }^{28,29}$ These results indicated larger tumor size and/or more lymph node metastasis correlated with more aggressive tumor and/or longer time interval between tumor formation and diagnosis or surgery, leading to shorter overall survival and poor outcome. However, both ER and PR positivity correlated with better prognosis. Hormone-receptor-positive $\mathrm{BC}$ patients tend to 

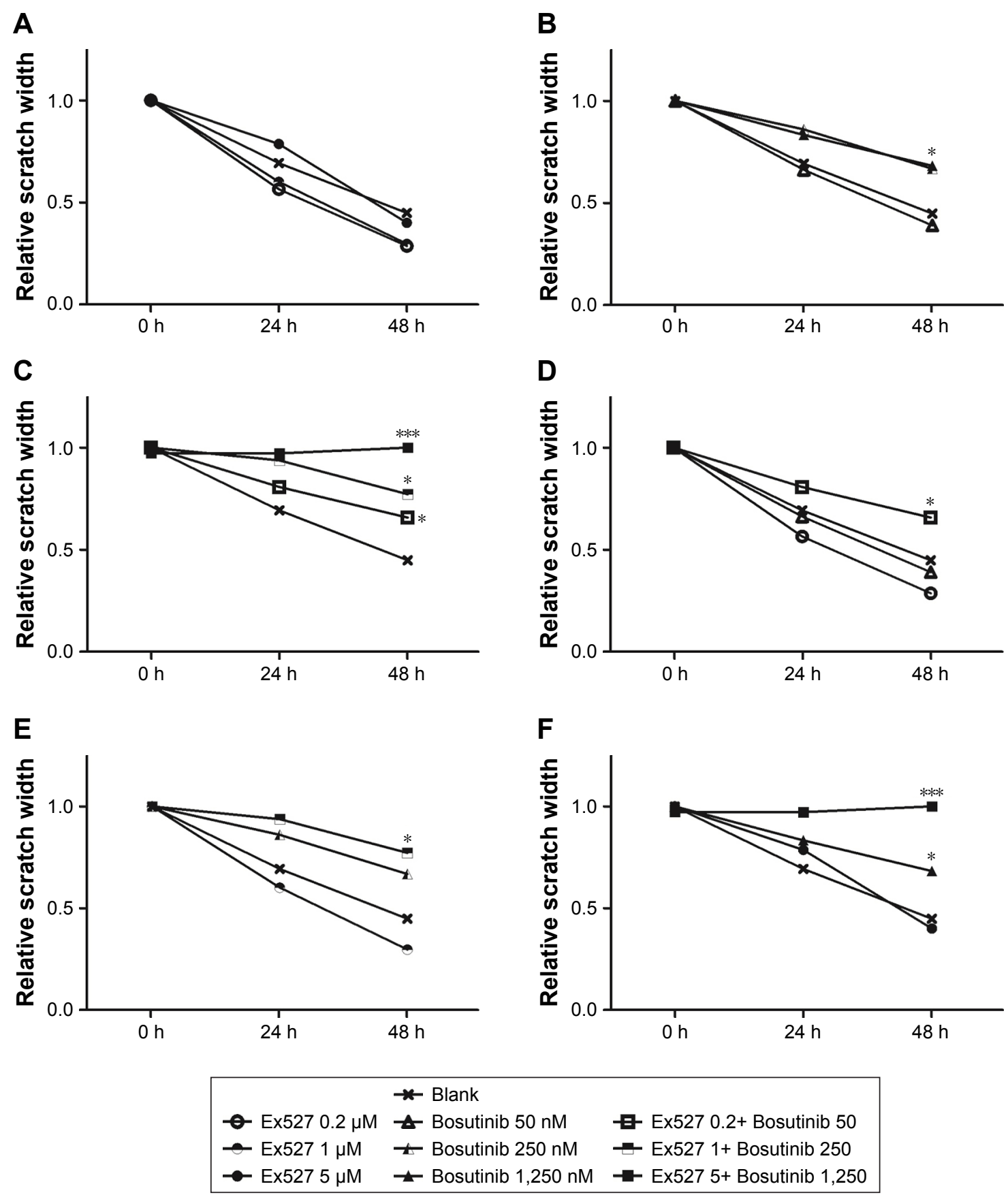

Figure 5 Wound healing assays indicate MCF-7 cell migration is suppressed by bosutinib.

Notes: Ex527 and bosutinib combination has increased effect on cell migration suppression. (A-C) Migration inhibition effect measured by wound healing assay of different concentrations of Ex527 (A), bosutinib (B), and their combinations (C). (D-F) Migration inhibition effect of low (D), medium (E), or high (F) concentration of Ex527, bosutinib, and their combinations. $* P$-value $<0.05$; $* * *$-value $<0.001$.

have longer survival after standard endocrine therapy. ${ }^{30}$ Since $\mathrm{T}$ and $\mathrm{N}$ category, ER, and PR were associated with each other, only $\mathrm{N}$ category and PR status showed independent effect on $\mathrm{BC}$ prognosis in multiple-factor analysis.

Strong SIRT1 + Src was defined as SIRT1 and/or Src overexpression, and was an ideal independent prognosis factor for human $\mathrm{BC}$ in both single- and multiple-factor $\mathrm{COX}$ regression analysis. Importantly, SIRT1 + Src showed better correlation with prognosis in LBC subgroup, while it did not have a statistical significant effect on survival in non-LBC subgroup. These results indicated that LBC patients with strong SIRT1 + Src level may need further stronger treatment with or after standard therapy. And also, as suggested Sirt and Src may have a potential interaction with hormone receptor 


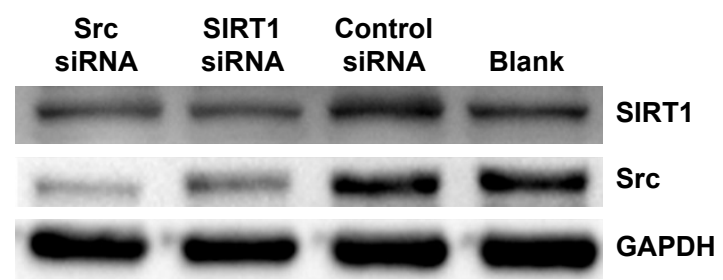

Figure 6 Both SIRTI and Src siRNA treatment shows SIRTI and Src protein expression suppression effect compared to control groups.

signaling pathway. Since Sirt and Src expression had no direct correlation with ER or PR status, this interaction may not be a direct regulator on protein expression level. Instead, SIRT1 and Src may play potential roles in LBC oncogenesis or endocrine therapy resistance development.

Through cell proliferation and migration assays, we found that SIRT1 inhibitor had a cell growth suppression effect and Src inhibitor suppressed LBC cell migration. The combination of these 2 inhibitors had an enhanced effect on cell migration inhibition. These results suggested that SIRT1 and Src may promote cell proliferation and migration separately, but had a synergistic effect on cell migration promotion.

We used SIRT1- and Src-specific siRNA to permanently knockdown SIRT1 and Src protein expression. We found both SIRT1 and Src siRNA treatment lead to downregulations of both SIRT1 and Src protein. A correlation between SIRT1 and Src expression was also found in tissue microarray analysis. Src was reported to suppress Sirt2 protein expression and phosphorylate Sirt2 at Tyr104 position, regulating the deacetylation activity of Sirt2. ${ }^{31}$ And SIRT1 suppresses SKIP/Src-enhanced RAR transactivation activity. ${ }^{32}$ SIRT1 and Src coregulate CXCR4 protein level in MCF-7 cells, indicating they share a functional crosstalk between their regulating pathways in this $\mathrm{BC}$ cell line..$^{33}$ All these results indicated that SIRT1 and Src may have a mutual regulation in LBC oncogenesis and development. Further studies are needed to investigate their mutual regulation mechanism and their associations with hormone receptor signaling pathway and endocrine therapy resistance.

\section{Conclusion}

In conclusion, this study has provided SIRT1 + Src combination as a novel independent LBC prognosis factor. We have further demonstrated that SIRT1 and Src may have a mutual regulation effect in $\mathrm{LBC}$ and that a combination of their inhibitors has a synergistic effect on MCF-7 cell migration. Further studies will be required to determine the full mechanism of SIRT1 and Src correlation and its potential for prevention and treatment of human cancers.

\section{Acknowledgments}

We would like to thank Dr Huang Bangxing and Dr Nie Xiu for their work on tissue microarrays evaluation. This work was supported by the National Natural Science Foundation of China (grant no 81001171) and the Key Technologies R\&D Program of Hubei Province (grant no 2007AA302B07).

\section{Disclosure}

The authors report no conflicts of interest in this work.

\section{References}

1. Stewart BW, Wild CP; International Agency for Research on Cancer, WHO. World Cancer Report 2014 [Online]. Geneva: WHO. Available from: http://www.thehealthwell.info/node/725845. Accessed January 13, 2018.

2. Sachs N, de Ligt J, Kopper O, et al. A living biobank of breast cancer organoids captures disease heterogeneity. Cell. 2018;172(1-2): 373.e10-386.e10.

3. Torre LA, Siegel RL, Ward EM, Jemal A. Global cancer incidence and mortality rates and trends-an update. Cancer Epidemiol Biomarkers Prev. 2016;25(1):16-27.

4. Lakhani SR, Ellis IO, Schnitt SJ, Tan PH, van de Vijver MJ. WHO Classification of Tumours of the Breast. 4th ed. Lyon, France: IARC Press; 2012.

5. Perou CM, Sorlie T, Eisen MB, et al. Molecular portraits of human breast tumours. Nature. 2000;406(6797):747-752.

6. Blander G, Guarente L. The Sir2 family of protein deacetylases. Annu Rev Biochem. 2004;73:417-435.

7. Saunders LR, Verdin E. Sirtuins: critical regulators at the crossroads between cancer and aging. Oncogene. 2007;26(37):5489-5504.

8. Yi YW, Kang HJ, Kim HJ, Kong Y, Brown ML, Bae I. Targeting mutant $\mathrm{p} 53$ by a SIRT1 activator YK-3-237 inhibits the proliferation of triple-negative breast cancer cells. Oncotarget. 2013;4(7):984-994.

9. Choi HK, Cho KB, Phuong NT, et al. SIRT1-mediated FoxO1 deacetylation is essential for multidrug resistance-associated protein 2 expression in tamoxifen-resistant breast cancer cells. Mol Pharm. 2013; 10(7):2517-2527.

10. Yeung F, Hoberg JE, Ramsey CS, et al. Modulation of NF- $\kappa B-$ dependent transcription and cell survival by the SIRT1 deacetylase. EMBO J. 2004;23(12):2369-2380.

11. Wang C, Yang W, Dong F, et al. The prognostic role of Sirt1 expression in solid malignancies: a meta-analysis. Oncotarget. 2017;8(39): 66343-66351.

12. Elangovan S, Ramachandran S, Venkatesan N. SIRT1 is essential for oncogenic signaling by estrogen/estrogen receptor $\alpha$ in breast cancer. Cancer Res. 2011;71(21):6654-6664.

13. Moore RL, Faller DV. SIRT1 represses estrogen-signaling, ligandindependent $\mathrm{ER} \alpha$-mediated transcription, and cell proliferation in estrogen-responsive breast cells. J Endocrinol. 2013;216(3):273-285.

14. Zhang S, Yu D. Targeting Src family kinases in anti-cancer therapies: turning promise into triumph. Trends Pharmacol Sci. 2012;33(3): $122-128$.

15. Elsberger B, Paravasthu DM, Tovey SM, Edwards J. Shorter diseasespecific survival of ER-positive breast cancer patients with high cytoplasmic Src kinase expression after tamoxifen treatment. J Cancer Res Clin Oncol. 2012;138(2):327-332.

16. Vallabhaneni S, Nair BC, Cortez V, et al. Significance of ER-Src axis in hormonal therapy resistance. Breast Cancer Res Treat. 2011;130(2): 377-385.

17. Allred DC, Harvey JM, Berardo M, Clark GM. Prognostic and predictive factors in breast cancer by immunohistochemical analysis. Mod Pathol. 1998;11(2):155-168. 
18. Maimaiti Y, Tan J, Liu Z, et al. Overexpression of cofilin correlates with poor survival in breast cancer: a tissue microarray analysis. Oncol Lett. 2017;14(2):2288-2294.

19. Solomon JM, Pasupuleti R, Xu L, et al. Inhibition of SIRT1 catalytic activity increases p53 acetylation but does not alter cell survival following DNA damage. Mol Cell Biol. 2006;26(1):28-38.

20. Boschelli DH, Ye F, Wang YD, et al. Optimization of 4-phenylamino3-quinolinecarbonitriles as potent inhibitors of Src kinase activity. J Med Chem. 2001;44(23):3965-3977.

21. Maimaiti Y, Jie T, Jing Z, et al. Aurora kinase A induces papillary thyroid cancer lymph node metastasis by promoting cofilin-1 activity. Biochem Biophys Res Commun. 2016;473(1):212-218.

22. Belsches-Jablonski AP, Biscardi JS, Peavy DR, Tice DA, Romney DA, Parsons SJ. Src family kinases and HER2 interactions in human breast cancer cell growth and survival. Oncogene. 2001;20(12): 1465-1475.

23. Peiró G, Ortiz-Martínez F, Gallardo A, et al. Src, a potential target for overcoming trastuzumab resistance in HER2-positive breast carcinoma. Br J Cancer. 2014;111(4):689-695.

24. Ghaffari A, Hoskin V, Szeto A, et al. A novel role for ezrin in breast cancer angio/lymphangiogenesis. Breast Cancer Res. 2014;16(5):438.

25. Matsumoto T, Jiang J, Kiguchi K, et al. Targeted expression of c-Src in epidermal basal cells leads to enhanced skin tumor promotion, malignant progression, and metastasis. Cancer Res. 2003;63(16):4819-4828.
26. Park SI, Zhang J, Phillips KA, et al. Targeting SRC family kinases inhibits growth and lymph node metastases of prostate cancer in an orthotopic nude mouse model. Cancer Res. 2008;68(9):3323-3333.

27. Olivotto IA, Gomi A, Bancej C, et al. Influence of delay to diagnosis on prognostic indicators of screen-detected breast carcinoma. Cancer. 2002;94(8):2143-2150.

28. Say CC, Donegan WL. Invasive carcinoma of the breast: prognostic significance of tumor size and involved axillary lymph nodes. Cancer. 1974;34(2):468-471.

29. Saadatmand S, Bretveld R, Siesling S, Tilanus-Linthorst MM. Influence of tumour stage at breast cancer detection on survival in modern times: population based study in 173,797 patients. BMJ. 2015;351:h4901.

30. Godolphin W, Elwood JM, Spinelli JJ. Estrogen receptor quantitation and staging as complementary prognostic indicators in breast cancer: a study of 583 patients. Int J Cancer. 1981;28(6):677-683.

31. Choi YH, Kim H, Lee SH, Jin YH, Lee KY. Src regulates the activity of SIRT2. Biochem Biophys Res Commun. 2014;450(2):1120-1125.

32. Kang MR, Lee SW, Um E, et al. Reciprocal roles of SIRT1 and SKIP in the regulation of RAR activity: implication in the retinoic acidinduced neuronal differentiation of P19 cells. Nucleic Acids Res. 2010; 38(3):822-831.

33. Andreou K, Rajendran R, Krstic-Demonacos M, Demonacos C. Regulation of CXCR4 gene expression in breast cancer cells under diverse stress conditions. Int J Oncol. 2012;41(6):2253-2259.
OncoTargets and Therapy

\section{Publish your work in this journal}

OncoTargets and Therapy is an international, peer-reviewed, open access journal focusing on the pathological basis of all cancers, potential targets for therapy and treatment protocols employed to improve the management of cancer patients. The journal also focuses on the impact of management programs and new therapeutic agents and protocols on

\section{Dovepress}

patient perspectives such as quality of life, adherence and satisfaction. The manuscript management system is completely online and includes a very quick and fair peer-review system, which is all easy to use. Visit http://www.dovepress.com/testimonials.php to read real quotes from published authors. 